\title{
Brain Reward Regulated by AMPA Receptor Subunits in Nucleus Accumbens Shell
}

\author{
Mark S. Todtenkopf, ${ }^{1}$ Aram Parsegian, ${ }^{1}$ Alipi Naydenov, ${ }^{2}$ Rachael L. Neve, ${ }^{3}$ Christine Konradi, ${ }^{2}$ and \\ William A. Carlezon Jr ${ }^{1}$ \\ ${ }^{1}$ Behavioral Genetics, ${ }^{2}$ Neuroplasticity, and ${ }^{3}$ Molecular Genetics Laboratories, Department of Psychiatry, Harvard Medical School, McLean Hospital, \\ Belmont, Massachusetts 02478
}

\begin{abstract}
Drugs of abuse alter expression of AMPA-type glutamate receptor subunits (GluRs) in the nucleus accumbens (NAc), a key component of brain reward systems. The impact of this regulation on general motivational states is unclear. Here, we used herpes simplex virus vectors to examine how transient increases in the expression of GluR1 or GluR2 protein in the shell component of NAc affect the rewarding impact of electrical stimulation of the medial forebrain bundle, as reflected by intracranial self-stimulation (ICSS) thresholds in rats. We found that elevated GluR1 in NAc shell increases ICSS thresholds, an effect similar to that caused by treatments that cause anhedonia and dysphoria (prodepressive effects) in rats and humans (e.g., drug withdrawal, $\kappa$-opioid agonists). In contrast, elevated GluR2 decreases ICSS thresholds, an effect similar to that caused by rewarding treatments (e.g., drugs of abuse). To confirm that viral vector-mediated elevations of GluR1 in the NAc shell produce molecular consequences that are different from those of elevated GluR2, we examined the expression of a set of drug-regulated genes $3 \mathrm{~d}$ after treatment using quantitative PCR. Elevated GluR1 was accompanied by sustained increases in the gene for GluR1, whereas elevated GluR2 was accompanied by decreases in prodynorphin. These data suggest that GluR1 and GluR2 in the NAc shell play opposing roles in the regulation of motivated behavior.
\end{abstract}

Key words: ICSS; glutamate; dynorphin; motivation; viral vector; rat

\section{Introduction}

AMPA-type glutamate receptors (AMPARs) are expressed ubiquitously in brain and composed of various combinations of glutamate receptor subunits 1-4 (GluR1-4) (Hollman et al., 1991; Malinow and Malenka, 2002). Drugs of abuse alter expression of GluRs in the nucleus accumbens (NAc) (Churchill et al., 1999), a key component of brain reward systems. Drug-induced alterations in GluR expression and AMPAR function in NAc could play an important role in addiction because this region integrates inputs from limbic and cortical regions, linking motivation with action (Mogenson and Yang, 1991). Although some studies have been designed to examine the consequences of altered GluR expression in the NAc, they generally involve interactions with drugs of abuse. For example, cocaine-induced elevations in GluR1 expression within the NAc correlate with sensitization to the locomotor-stimulating effects of the drug (Churchill et al., 1999). Elevated GluR2 in the NAc has been linked to expression of $\Delta$ FosB (a protein regulated by drugs of abuse) and hypersensitivity to cocaine (Kelz et al., 1999). Viral vector-mediated elevations of GluR1 or GluR2 in the NAc cause enhanced behavioral responsiveness to cocaine, although the consequences are mark-

Received July 19, 2006; revised Aug. 31, 2006; accepted Sept. 28, 2006.

This work was supported by National Institute on Drug Abuse Grants DA12736 (W.A.C.), DA19152 (C.K.), and DA018037 (M.S.T.).

Correspondence should be addressed to William A. Carlezon Jr, Department of Psychiatry, McLean Hospital, MRC 217, 115 Mill Street, Belmont, MA 02478. E-mail: bcarlezon@mclean.harvard.edu. DOI:10.1523/JNEUROSCI.3070-06.2006

Copyright $\odot 2006$ Society for Neuroscience $\quad$ 0270-6474/06/2611665-05\$15.00/0 edly different: elevated GluR1 makes a subthreshold dose of cocaine aversive, whereas elevated GluR2 makes the same dose rewarding (Kelz et al., 1999). Interestingly, although elevated expression of either GluR1 or GluR2 in the NAc reduces drug seeking in rats, only increased GluR1 is correlated with resistance to reinstatement (Sutton et al., 2003). This finding raises the possibility that alterations in expression of these subunits in the NAc have differential consequences that can be difficult to distinguish in tests in which a single behavioral outcome (e.g., increased locomotor activity, reduced drug seeking) could reflect a variety of motivational states. Behavioral studies that do not involve drug exposure or dependence might reveal more fundamental relationships between AMPAR subunit composition and motivation, which is dysregulated in addiction and other psychiatric conditions (Nestler and Carlezon, 2006).

We examined how alterations in GluR expression modeling those acquired through repeated drug exposure affect intracranial self-stimulation (ICSS), an operant task in which the magnitude of the reinforcer (brain stimulation reward) is precisely controlled (Wise, 1996). Rats were implanted with stimulating electrodes aimed at the medial forebrain bundle (MFB); stimulation in this area activates the mesolimbic system and produces high rates of responding (lever pressing) without satiation, which can complicate studies that involve other types of rewards (e.g., food, sexual behavior, drugs of abuse) (Wise, 1996). ICSS thresholds, the frequency at which the stimulation becomes rewarding, are decreased by drugs of abuse (Wise, 1996) and increased by treatments with aversive or dysphoric effects in humans, includ- 
ing drug withdrawal (Markou et al., 1992) and $\kappa$-opioid agonists (Todtenkopf et al., 2004). Once ICSS thresholds were stable, we used viral-mediated gene transfer to increase GluR1 or GluR2 expression in the shell component of the NAc. To confirm that elevated GluR1 expression produces molecular consequences that are distinguishable from those of elevated GluR2, we examined the expression of a set of NAc genes encoding proteins previously associated with drug-dependent changes in behavior.

\section{Materials and Methods}

Rats. Sixty-eight male Sprague Dawley rats (Charles River Laboratories, Wilmington, MA) were used in these studies. Rats were housed individually, weighed $325-375 \mathrm{~g}$ at the time of stereotaxic surgery, and were maintained on a 12 h light (7:00 A.M. to 7:00 P.M.)/dark cycle with ad libitum access to food and water, except during testing. Experiments were conducted in accordance with the National Institutes of Health Guide for the Care and Use of Laboratory Animals (1996) and approved by McLean Hospital.

ICSS. Thirty-eight rats were anesthetized with intraperitoneal injections of ketamine plus xylazine $(80 \mathrm{mg} / \mathrm{kg}$ plus $12 \mathrm{mg} / \mathrm{kg}$; Sigma, St. Louis, MO) and given subcutaneous atropine sulfate $(0.25 \mathrm{mg} / \mathrm{kg})$ to reduce bronchial secretions. Monopolar, stainless steel electrodes $(0.250$ $\mathrm{mm}$ diameter; Plastics One, Roanoke, VA) were implanted in the right MFB at a $10^{\circ}$ angle (final electrode tip coordinates: $3.0 \mathrm{~mm}$ posterior to bregma, $1.6 \mathrm{~mm}$ lateral from midsagittal suture, and $7.6 \mathrm{~mm}$ below dura) (Paxinos and Watson, 1998). The electrodes were coated with polyamide insulation, except at the flattened tip. Simultaneously, rats were implanted with bilateral guide cannulas (20 gauge; Plastics One) aimed at the NAc shell at an $18^{\circ}$ angle (final injection site coordinates: $1.2 \mathrm{~mm}$ anterior to bregma, $0.8 \mathrm{~mm}$ lateral from midsagittal suture, and $6.9 \mathrm{~mm}$ below dura) (Paxinos and Watson, 1998). Skull screws (one of which served as the ground) and the electrodes and cannulas were secured to the skull with dental acrylic.

One week later, the rats were trained to respond for brain stimulation as described previously (Todtenkopf et al., 2004). Briefly, each lever press earned a $0.5 \mathrm{~s}$ train of square-wave cathodal pulses $(0.1 \mathrm{~ms}$ pulse duration, $141 \mathrm{~Hz})$. The stimulation current $(100-300 \mu \mathrm{A})$ was adjusted to the lowest value that would sustain reliable responding ( $\geq 40$ rewards per minute). Once an appropriate current was found for each rat, it was held constant. Each rat was then adapted to brief tests (1 min trials) with each of a descending series of 15 frequencies. For each frequency tested, there was an initial $5 \mathrm{~s}$ phase during which noncontingent stimulation was given, followed by a $50 \mathrm{~s}$ test phase during which responding was quantified. After the test phase, there was a $5 \mathrm{~s}$ time-out period. The stimulation frequency was then lowered by $\sim 10 \%\left(0.05 \log _{10}\right.$ units $)$, and another trial was started. After responding had been evaluated at each of the 15 frequencies (a "pass"), the procedure was repeated such that each rat was given four passes per day (60 min). To characterize the functions relating response strength to reward magnitude, a least-squares line of best fit was plotted across the frequencies that sustained responding at 20 , $30,40,50$, and $60 \%$ of the maximum rate. The ICSS threshold was defined as the frequency at which this line intersected the $x$-axis (theta-0) (Miliaressis et al., 1986); theoretically, this represents the point at which the stimulation becomes rewarding. Mean ICSS thresholds were determined for each training day by averaging the threshold for passes 2-4: the first pass served as a warm up and was discarded. Bilateral microinjection of viral vectors was performed when mean ICSS thresholds varied by $<15 \%$ over five consecutive training sessions. The mean threshold of the last five training sessions served as the baseline threshold for the remainder of the study.

Viral vector microinjections and testing. Herpes simplex virus (HSV) vectors encoding GluR1 (HSV-GluR1), GluR2 (HSV-GluR2), and $\beta$-galactosidase (a control protein; HSV-LacZ) were produced as described previously (Carlezon et al., 1997; Kelz et al., 1999; Sutton et al., 2003). Vector titers were $4.0 \times 10^{7}$ infectious units $/ \mathrm{ml}$. Immediately after the final ICSS training session, rats were anesthetized with isofluorane and placed in a stereotaxic apparatus. Rats received bilateral (2.0 $\mu \mathrm{l} /$ side) microinjections of the vectors into the NAc over $10 \mathrm{~min}$, and the syringes were left in place for an additional 5 min to allow diffusion. Beginning $24 \mathrm{~h}$ later, rats were tested for ICSS on 8 consecutive days. Mean thresholds for each day were calculated and compared with baseline thresholds. Effects of gene transfer on ICSS thresholds or maximal response rates over the $8 \mathrm{~d}$ test period were evaluated with separate two-way ANOVAs (treatment $x$ day) with repeated measures; significant effects were analyzed using post hoc Fisher's protected $t$ tests.

Quantitative PCR. A separate group of 30 rats received microinjections of HSV-GluR1 $(n=10)$, HSV-GluR2 $(n=10)$, or HSV-LacZ $(n=10)$ into the NAc shell as described above. This work was designed to confirm that elevation of these proteins has differential effects on gene expression. We focused on the genes for dynorphin, cAMP response elementbinding protein (CREB), GluR1, and GluR2 because of their previous association with drugs of abuse (Nestler and Carlezon, 2006), as well as $\mu$ - and $\delta$-opioid receptors because of the potential involvement of endogenous opioids in ICSS (Wise, 1996). These rats were killed by decapitation $3 \mathrm{~d}$ after gene transfer, a time of strong behavioral effects of both elevated GluR1 and GluR2 expression, and the brains were immediately frozen in $-70^{\circ} \mathrm{C}$ isopentane. Tissue punches from the NAc shell were taken bilaterally using a $1 \mathrm{~mm}$ sample corer; all brains were used with the exception of the brain from one rat that received HSV-LacZ, which was sectioned to depict vector-mediated expression of $\beta$-galactosidase (see below). cDNA was synthesized from $1 \mu \mathrm{g}$ of total RNA with the SuperScript First-Strand Synthesis System for real-time quantitative PCR (QPCR) (Invitrogen, Carlsbad CA) and an oligonucleotide deoxythymidine primer. A primer set for each gene was designed with the Primer3 software (www-genome.wi.mit.edu/cgi-bin/primer/primer3.cgi.) for amplicons of 150-250 base pairs. Melt-curve analysis and PAGE were used to confirm the specificity of each primer pair. The iQ SYBR Green Supermix (Bio-Rad, Hercules CA) was used; the experiments were conducted with a MyiQ real-time PCR detection system (Bio-Rad) in a volume of $20 \mu \mathrm{l}$ with $4 \mu \mathrm{l}$ of $1: 10$ diluted cDNA samples and $0.3 \mu \mathrm{M}$ primers. The PCR cycling conditions were initially $95^{\circ} \mathrm{C}$ for 5 min, followed by 39 cycles of $94^{\circ} \mathrm{C}$ for $10 \mathrm{~s}, 57^{\circ} \mathrm{C}$ for $15 \mathrm{~s}$, and $72^{\circ} \mathrm{C}$ for $20 \mathrm{~s}$. Data were collected between $72^{\circ} \mathrm{C}$ and $84^{\circ} \mathrm{C}$ depending on amplicon melt temperature. A melt-curve analysis was performed at the end of each Q-PCR experiment from $60^{\circ} \mathrm{C}$ to $95^{\circ} \mathrm{C}$. Dilution curves were generated for each primer pair in every experiment by diluting cDNA from a vehicle sample to a final concentration of $1.00,0.2,0.04$, and 0.008 . The logarithm of the dilution values was plotted against the cycle values for the standard curve. Blanks were run with each dilution curve; dilution curves, blanks, and samples were run in duplicate. Reported values were normalized to the internal standards $\beta$-actin (Entrez Gene ID 81822) and general transcription factor $2 \beta$ (Entrez Gene ID 81673), neither of which was regulated. Group differences in gene expression were analyzed using separate one-way ANOVAs for each gene; significant effects were analyzed using post hoc Fisher's protected $t$ tests.

Histology. Rats from the ICSS studies were killed by decapitation after the last test, and brains were immediately frozen in $-70^{\circ} \mathrm{C}$ isopentane. Sections $(50 \mu \mathrm{m})$ were thaw mounted onto slides, submerged in $4 \%$ paraformaldehyde $\left(4^{\circ} \mathrm{C}\right)$ for $10 \mathrm{~min}$, and rinsed three times for $10 \mathrm{~min}$ in $0.1 \mathrm{M}$ phosphate buffer solution (PB). Sections including the MFB were stained with cresyl violet to confirm electrode placement. Sections through the NAc shell were stained using immunocytochemistry for tyrosine hydroxylase (TH) as described previously (Carlezon et al., 1997) to confirm microinjection site placement. Briefly, the sections were incubated overnight in PB with $0.2 \%$ Triton X-100 (PBTx) and primary polyclonal antiserum (rabbit anti-TH, 1:5000; Chemicon, Temecula, CA), followed by $1 \mathrm{~h}$ in PBTx containing biotinylated goat anti-rabbit IgG antibody (1:200; Vector Laboratories, Burlingame, CA), followed by $1 \mathrm{~h}$ in avidin-biotin complex reagent (Vector Laboratories), followed by 5-10 min in PB containing $0.05 \% 3^{\prime}, 3^{\prime}$-diaminobenzidine tetrahydrochloride (Sigma) with $0.01 \% \mathrm{H}_{2} \mathrm{O}_{2}$. After air drying, sections were counterstained with cresyl violet and coverslipped. Histology was rated by an observer who was unaware of the treatment conditions; only rats with electrode placement in the MFB and bilateral microinjection placement in the intermediate zone of the NAc shell (as evident by the TH staining) were retained. In addition, one rat that received HSV-LacZ was used to 

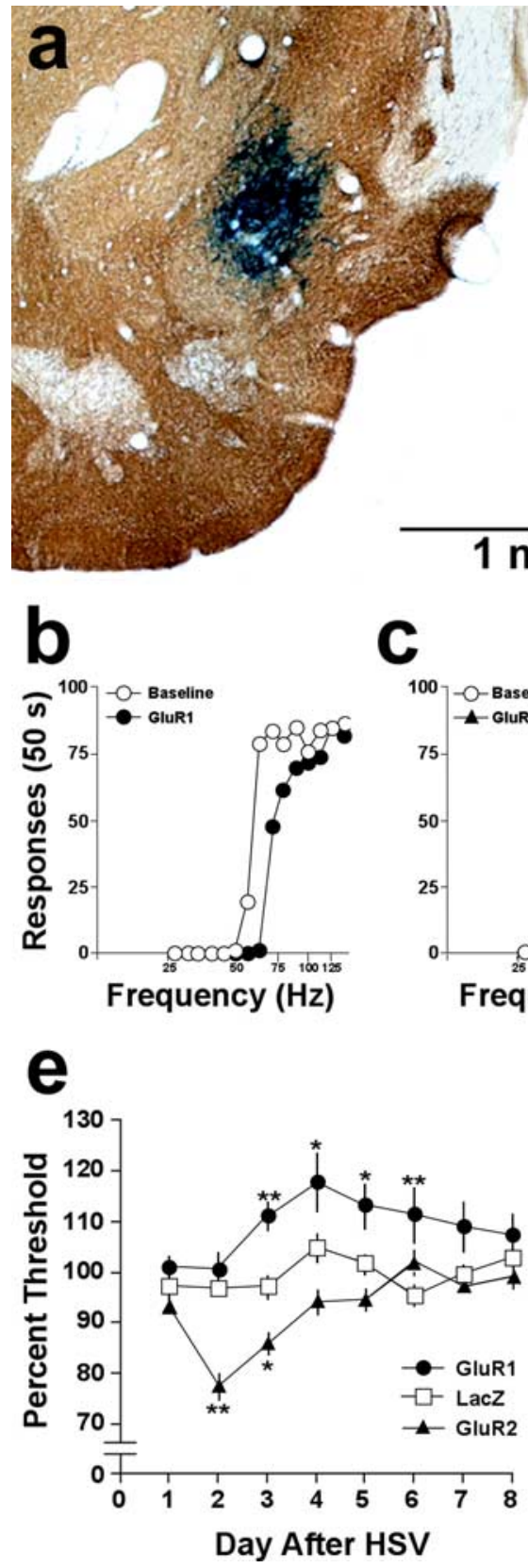

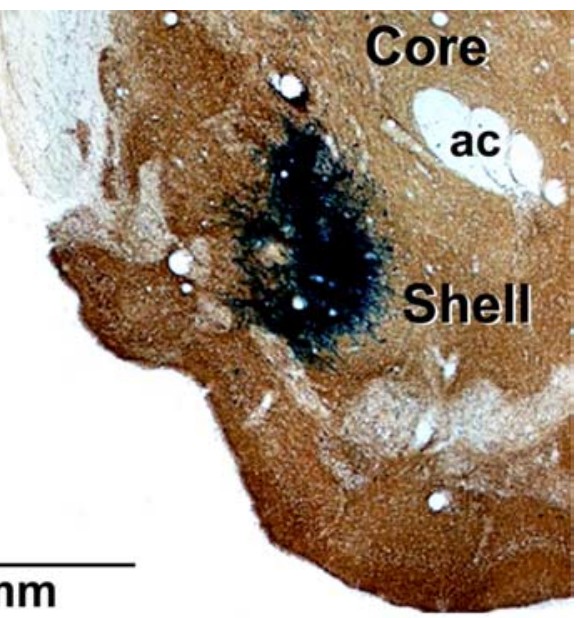

d

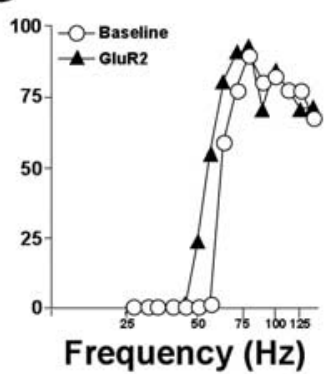

f
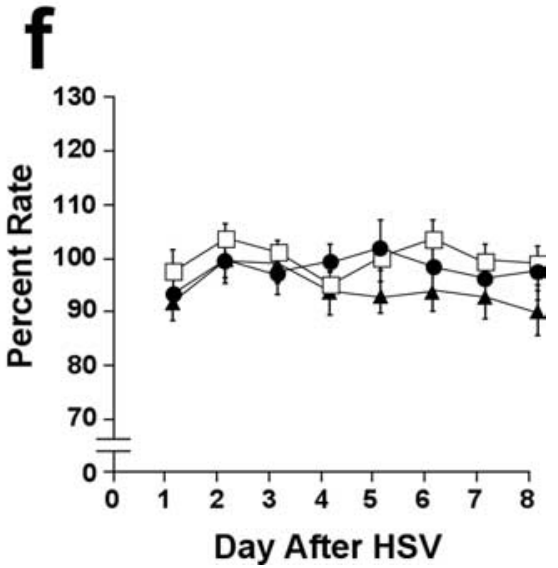

Figure 1. Effects of HSV vector-mediated alterations in gene expression in the NAc shell on ICSS. $\boldsymbol{a}$, Expression of $\beta$-galactosidase, induced by bilateral microinjections of HSV-LacZ into the NAc (ac) shell, $3 \mathrm{~d}$ after gene transfer in a brain section costained for TH (magnification, $40 \times$ ). $\boldsymbol{b}-\boldsymbol{d}$, Elevated GluR1 $(\boldsymbol{b})$ expression in this region caused rightward shifts in ratefrequency functions, whereas elevated GluR2 (c) expression caused leftward shifts and $\beta$-galactosidase ( $\boldsymbol{d}$ ) had no effect. Data are from representative rats tested $3 \mathrm{~d}$ after gene transfer; for clarity, only the third of four daily rate-frequency determinations is shown. $\boldsymbol{e}$, Effect of gene transfer on mean ( \pm SEM) ICSS thresholds in $1 \mathrm{~h}$ test sessions across the $8 \mathrm{~d}$ test period. $\boldsymbol{f}$, Elevated GluR2 decreased ICSS thresholds, whereas elevated GluR1 increased thresholds relative to rats treated with HSV-LacZ $\left(F_{(14,182)}=2.15\right.$; $p<0.02$ ), although none of the treatments affected response rates. Data are expressed as percentage of pre-gene transfer baselines. ${ }^{*} p<0.05,{ }^{* *} p<0.01$ (Fisher's tests).

depict bilateral elevation of $\beta$-galactosidase in the NAc shell $3 \mathrm{~d}$ after gene transfer, as described previously (Carlezon et al., 1997).

\section{Results}

Bilateral microinjections of the viral vectors cause elevated transgene expression restricted to the NAc shell (Fig. 1a). Previous work with these same vectors has demonstrated that protein expression peaks $3 \mathrm{~d}$ after gene transfer, is dissipating by day 7 , and is virtually undetectable by day 10 (Carlezon et al., 1997; Kelz et al., 1999; Sutton et al., 2003). Data from nine rats were eliminated from the ICSS studies because the viral microinjections were located outside the NAc shell. These rats were distributed across the treatment conditions, and it was not possible to incorporate them into homogenous control groups because there was no systematic pattern of regions affected by the missed placements. The final number of rats retained was 11 (HSVGluR1), 8 (HSV-GluR2), and 10 (HSV-LacZ).

Over the $8 \mathrm{~d}$ test period, ICSS thresholds depended on an interaction of viral vector treatment and time $\left(F_{(14,182)}=\right.$ 2.15; $p<0.02$ ). Elevated GluR1 expression in the NAc shell caused rightward shifts in response rate-stimulation frequency functions (Fig. 1b) and increases in ICSS thresholds that peaked $4 \mathrm{~d}$ after gene transfer, and returned to normal by day 7 (Fig. 1e). Compared with rats treated with HSV-LacZ, ICSS thresholds were significantly higher in rats treated with HSVGluR1 on day 3 ( $p<0.01$, Fisher's protected $t$ test), day $4(p<0.05)$, day 5 ( $p<$ $0.05)$, and day $6(p<0.01)$. In contrast, elevated GluR2 expression in the NAc shell caused leftward shifts in rate-frequency functions (Fig. 1c) and decreases in ICSS thresholds (Fig. 1e). The effect of GluR2 peaked and normalized more quickly than the effect of GluR1: compared with rats treated with HSV-LacZ, ICSS thresholds were significantly lower in rats treated with HSV-GluR2 on day $2(p<0.01)$ and day 3 $(p<0.05)$ and had returned to normal by day 4 . None of the viral vector treatments altered response rates at any time point (Fig. $1 f$ ).

Q-PCR analysis of NAc shell dissections (Fig. 2, inset) demonstrated that viral-mediated elevations of GluR1 had consequences on gene expression in the NAc shell that were different from those of GluR2. Of the genes studied, elevated expression of GluR1 protein was associated only with a change in GluR1 gene expression $\left(F_{(2,26)}=6.03 ; p<0.01\right)$, which was significantly increased $(p<0.01)$ (Fig. 2). Elevated expression of GluR2 altered prodynorphin expression $\left(F_{(2,26)}=4.60 ; p<\right.$ $0.02)$, which was significantly decreased $(p<0.05)$ (Fig. 2). Despite strong GluR2 protein expression $3 \mathrm{~d}$ after HSV-GluR2 (Carlezon et al., 1997; Kelz et al., 1999; Sutton et al., 2003), GluR2 gene expression was already returning to baseline levels at this time point (Fig. 2).

There were no systematic differences in the placement of MFB stimulating electrodes among groups (Fig. 3).

\section{Discussion}

Elevated expression of GluR1 in the NAc shell increases ICSS thresholds, whereas elevated GluR2 decreases them. The effect of 
GluR2 on ICSS is qualitatively similar to that caused by drugs of abuse (Wise, 1996), suggesting that it reflects increases in the rewarding impact of the stimulation. In contrast, the effect of GluR1 is qualitatively similar to that caused by prodepressive treatments including drug withdrawal (Markou et al., 1992) and $\kappa$-opioid receptor agonists (Wadenberg, 2003; Todtenkopf et al., 2004), suggesting that it reflects decreases in the rewarding impact of the stimulation. These findings indicate that elevated expression of GluR1 and GluR2 in the NAc shell have markedly different consequences on motivated behavior. Moreover, they confirm previous observations that elevated GluR1 and GluR2 expression in the NAc shell have opposite effects in cocaine placeconditioning studies (Kelz et al., 1999) and extend the generalizability of these effects to behaviors that are not motivated by drugs of abuse.

The mechanisms by which alterations in GluR1 and GluR2 expression in the NAc shell affect motivated behavior are not known. Increased GluR1 expression favors formation of GluR1homomeric (or GluR1-GluR3 heteromeric) AMPARs, which are calcium $\left(\mathrm{Ca}^{2+}\right)$ permeable (Hollman et al., 1991; Malinow and Malenka, 2002). In contrast, GluR2 contains a motif that prevents $\mathrm{Ca}^{2+}$ influx; thus, increased expression of GluR2 would favor formation of GluR2-containing $\mathrm{Ca}^{2+}$-impermeable AMPARs (and theoretically decrease the number of $\mathrm{Ca}^{2+}$ permeable AMPARs). The presence of GluR2 also indirectly controls AMPAR function by nullifying the ability of CaMKIIinduced GluR1 phosphorylation to regulate channel conductance (Oh and Derkach, 2005). Thus, GluR2-containing AMPARs have physiological properties that render them functionally distinct from those lacking this subunit. Because $\mathrm{Ca}^{2+}$ plays a role in both neuronal depolarization and gene regulation (Carlezon and Nestler, 2002), alterations in GluR expression and AMPAR subunit composition in the NAc shell likely initiate physiological and molecular responses, which presumably interact to alter motivation. We examined secondary changes in a small number of genes that encode drug-regulated proteins. These studies were not intended to be exhaustive or to establish cause-effect relationships; rather, they were designed to confirm that increased expression of GluR1 in NAc shell causes molecular adaptations that can be distinguished from those of GluR2, because in some tests, viral vector-induced increases in these subunits produce similar behavioral outputs (Sutton et al., 2003). We found that elevated GluR2 caused significant decreases in prodynorphin expression. This effect is potentially important because previous work has established associations among dynorphin, $\kappa$-receptors, and anhedonia (Todtenkopf et al., 2004; Nestler and Carlezon, 2006). This finding raises the possibility that reduced expression of an opioid that normally opposes reward in the NAc shell (Nestler and Carlezon, 2006) contributes to increases in the rewarding impact of the MFB stimulation. Interestingly, although it has been shown that this same HSV-GluR2 vector construct induces strong GluR2 protein expression $3 \mathrm{~d}$ after gene transfer (Carlezon et al., 1997; Kelz et al., 1999; Sutton et al., 2003), GluR2 gene expression was returning to normal at this time point, suggesting tight regulation within the NAc shell. In contrast, elevated ex-

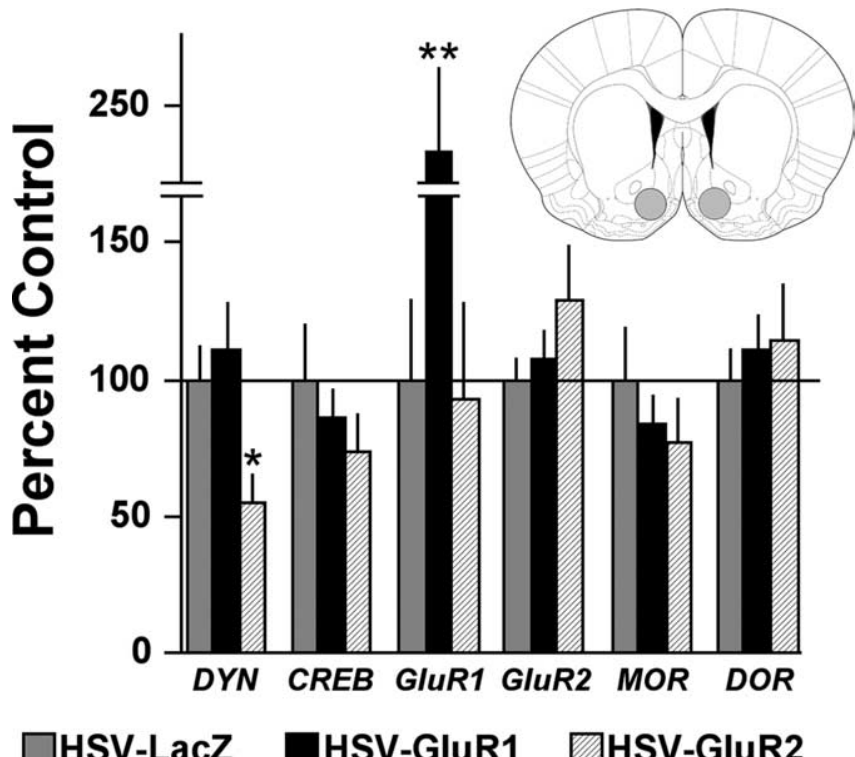

$\square$ HSV-LacZ DHSV-GluR1 $\square$ HSV-GluR2

Figure 2. Effects of HSV vector-mediated alterations in gene expression in the NAc shell, as measured by Q-PCR. Elevated GluR2 expression decreased prodynorphin (DYN) mRNA, whereas elevated GluR1 expression increased GluR1 mRNA. Data are mean ( \pm SEM) levels of mRNA normalized to $\beta$-actin and general transcription factor $2 \beta$ (GTF- $2 \beta$ ) and expressed as percentage of HSV-LacZ control. ${ }^{*} p<0.05,{ }^{* *} p<0.01$ (Fisher's tests). Inset, Areas of the NAc shell targeted for dissection (gray shading). MOR, $\mu$-Opioid receptor gene; DOR, $\delta$-opioid receptor gene.

Figure 3. Histological reconstruction of ICSS electrode placements for each treatment group. Headings indicate the gene that was virally transferred; the circles localize the electrode tips. The distance posterior to bregma (in millimeters) is indicated.

pression of GluR1 protein was associated only with elevated GluR1 gene expression. This might indicate that the gene for GluR1 is not as tightly regulated as the gene for GluR2 in response to viral vector-mediated overexpression, or that elevated GluR1 protein has feedforward effects on GluR1 gene expression. Differences in the time course of GluR1 and GluR2 gene expression fit well with the behavioral data: the effects of elevated GluR2 expression peaked earlier and returned to normal sooner than those of GluR1. Regardless, alterations in GluR1 protein and $\mathrm{Ca}^{2+}$-permeable AMPARs on the surface of NAc shell neurons could increase firing rates, which have been previously associated with alterations in responsiveness to rewarding stimuli such as drugs of abuse. For example, elevated CREB expression in the NAc shell increases firing rates and opposes the effects of cocaine (Dong et al., 2006). These effects are qualitatively similar, in 
terms of effects on reward function, as those induced here by elevated GluR1 expression. Furthermore, we have shown that reduction in $\mathrm{Ca}^{2+}$ flux in the NAc has reward-related effects (Chartoff et al., 2006b), consistent with the hypothesis that the behavioral consequences of elevated GluR2 expression involve AMPAR ion permeability.

The present studies should be differentiated from studies in which systemic drug administration is used to produce "sensitized" animals, even if the treatment regimens are sufficient to induce alterations in GluR expression within the NAc (Churchill et al., 1999). Systemic drug administration induces molecular alterations throughout the brain, making it difficult to isolate the significance of changes in individual GluR subunits in the NAc shell against a background of other neuroadaptations. Previous work indicates that elevations of GluR1 in the VTA that model those caused by repeated drug administration induce a "traditional" sensitized response to drugs (enhanced drug reward) (Carlezon et al., 1997). In contrast, elevations of GluR1 in the NAc shell that model those caused by repeated drug administration induce what might be considered an "atypical" sensitized response to drugs (enhanced drug aversion) (Kelz et al., 1999). Thus, elevation of a protein such as GluR1 should not be expected to produce uniform effects throughout the brain. The use of viral vectors to alter GluR1 or GluR2 selectively enables detailed analysis of the significance of altered AMPAR subunit composition within discrete brain areas.

The fact that elevated expression of GluR1 and GluR2 within the NAc shell have opposite effects on behavior has important implications for addiction and other psychiatric conditions (e.g., depression, bipolar disorder) characterized by dysregulated motivation (Nestler and Carlezon, 2006). AMPAR-related neuroadaptations that favor altered synaptic efficiency such as long-term potentiation (Malinow and Malenka, 2002; Oh and Derkach, 2005; Dong et al., 2006) in the NAc shell might be expected to cause fundamental changes in the function of this region, thereby increasing or decreasing the incentive value of stimuli in the environment (Mogenson and Yang, 1991). In some cases, elevated expression of GluR1 or GluR2 in the NAc shell might produce similar behavioral outputs (e.g., decreased drug seeking) (Sutton et al., 2003) that reflect dissimilar motivational states by altering the balance among reward, aversion, and satiation. One reason ICSS might have a unique ability to distinguish between the consequences of elevated GluR1 and GluR2 is because it is impervious to satiety: rodents will self-stimulate at high rates for long periods of time (Wise, 1987). Additionally, progressive increases in doses of drugs such as cocaine cause progressive increases in ICSS responding (Wise, 1996), whereas they decrease rates of responding for intravenous cocaine (Wise et al., 1995), suggesting satiety. With ICSS, each pulse of rewarding stimulation is brief $(0.5 \mathrm{~s})$ and immediately extracted by the anode, so there are no enduring after-effects (unlike other rewards, including drugs of abuse or food). Because satiety cannot explain treatmentinduced decreases in ICSS response rates, whereas it can explain some types of treatment-induced decreases in drug seeking, this model may be particularly useful for differentiating between decreases in responding caused by reward-like and aversive-like motivational states. ICSS also complements locomotor activity studies, because locomotion can be stimulated by either rewarding stimuli (e.g., cocaine) (Churchill et al., 1999) or aversive stim- uli (e.g., precipitated opiate withdrawal) (Chartoff et al., 2006a). Regardless, this work demonstrates that physiological adaptations accompanying altered GluR expression and AMPAR subunit composition can be translated into meaningful changes in complex motivated behaviors.

\section{References}

Carlezon Jr WA, Nestler EJ (2002) Upregulation of the AMPA receptor subunit GluR1 in the midbrain: a trigger for sensitization? Trends Neurosci 25:610-615.

Carlezon Jr WA, Boundy VA, Haile CN, Lane SB, Kalb RG, Neve RL, Nestler EJ (1997) Sensitization to morphine induced by viral-mediated gene transfer. Science 277:812-814.

Chartoff EH, Mague SD, Barhight MF, Smith AM, Carlezon Jr WA (2006a) Behavioral and molecular effects of dopamine D1 receptor stimulation during naloxone-precipitated morphine withdrawal. J Neurosci 26:6450-6457.

Chartoff EH, Pliakas AM, Carlezon Jr WA (2006b) Microinjection of the L-type calcium channel antagonist diltiazem into the nucleus accumbens shell increases cocaine reward. Biol Psychiatry 59:1236-1239.

Churchill L, Swanson CJ, Urbina M, Kalivas PW (1999) Repeated cocaine alters glutamate receptor subunit levels in the nucleus accumbens and ventral tegmental area of rats that develop behavioral sensitization. J Neurochem 72:2397-2403.

Dong Y, Green T, Saal D, Marie H, Neve R, Nestler EJ, Malenka RC (2006) CREB modulates excitability of nucleus accumbens neurons. Nat Neurosci 9:475-477.

Hollmann M, Hartley M, Heinemann S (1991) $\mathrm{Ca}^{2+}$ permeability of KAAMPA-gated glutamate receptor channels depends on subunit composition. Science 252:851-853.

Kelz MB, Chen JS, Carlezon Jr WA, Whisler K, Gilden L, Steffen C, Zheng YJ, Marotti L, Self DW, Tkatch T, Baranauskas G, Surmeier DJ, Neve RL, Duman RS, Picciotto MR, Nestler EJ (1999) Expression of the transcription factor $\Delta$ FosB in the brain controls sensitivity to cocaine. Nature 401:272-276.

Malinow R, Malenka RC (2002) AMPA receptor trafficking and synaptic plasticity. Annu Rev Neurosci 25:103-125.

Markou A, Hauger RL, Koob GF (1992) Desmethylimipramine attenuates cocaine withdrawal in rats. Psychopharmacology (Berl) 109:305-314.

Miliaressis E, Rompre P-P, Laviolette P, Philippe L, Coulombe D (1986) The curve-shift paradigm in self-stimulation. Physiol Behav 37:85-91.

Mogenson GJ, Yang CR (1991) The contribution of basal forebrain to limbic-motor integration and the mediation of motivation to action. Adv Exp Med Biol 295:267-290.

Nestler EJ, Carlezon Jr WA (2006) The mesolimbic dopamine reward circuit in depression. Biol Psychiatry 59:1151-1159.

Oh MC, Derkach VA (2005) Dominant role of the GluR2 subunit in regulation of AMPA receptors by CaMKII. Nat Neurosci 8:853-854.

Paxinos G, Watson C (1998) The rat brain in stereotaxic coordinates. San Diego, CA: Academic.

Sutton MA, Schmidt EF, Choi KH, Schad CA, Whisler K, Simmons D, Karanian DA, Monteggia LM, Neve RL, Self DW (2003) Extinction-induced upregulation in AMPA receptors reduces cocaine-seeking behaviour. Nature 421:70-75.

Todtenkopf MS, Marcus JF, Portoghese PS, Carlezon Jr WA (2004) Effects of $\kappa$-opioid ligands on intracranial self-stimulation in rats. Psychopharmacology (Berl) 172:463-470.

Wadenberg ML (2003) A review of the properties of spiradoline: a potent and selective kappa-opioid receptor agonist. CNS Drug Rev 9:187-198.

Wise RA (1987) Intravenous drug self-administration: a special case of positive reinforcement. In: Methods of assessing the reinforcing properties of abused drugs (M.A. Bozarth, ed), pp 117-141. New York: Springer

Wise RA (1996) Addictive drugs and brain stimulation reward. Annu Rev Neurosci 19:319-340.

Wise RA, Newton P, Leeb K, Burnette B, Pocock D, Justice Jr JB (1995) Fluctuations in nucleus accumbens dopamine concentration during intravenous cocaine self-administration in rats. Psychopharmacology 120: $10-20$. 